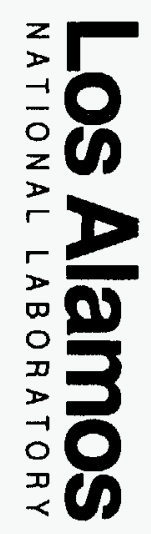

This report was prepared as an account of work sponsored by an agency of the United States Government. Neither the United States Government nor any agency thereof, nor any of their employees, makes any warranty, express or implied, or assumes any legal liability or responsibility for the accuracy, completeness, or usefulness of any information, apparatus, product, or process disclosed, or represents that its use would not infringe privately owned rights. Reference herein to any specific commercial product, process, or service by trade name, trademark, manufacturer, or otherwise does not necessarily constitute or imply its endorsement, recommendation, or favoring by the United States Government or any agency thereof. The views and opinions of authors expressed herein do not necessarily state or reflect those of the United States Government or any agency thereof.

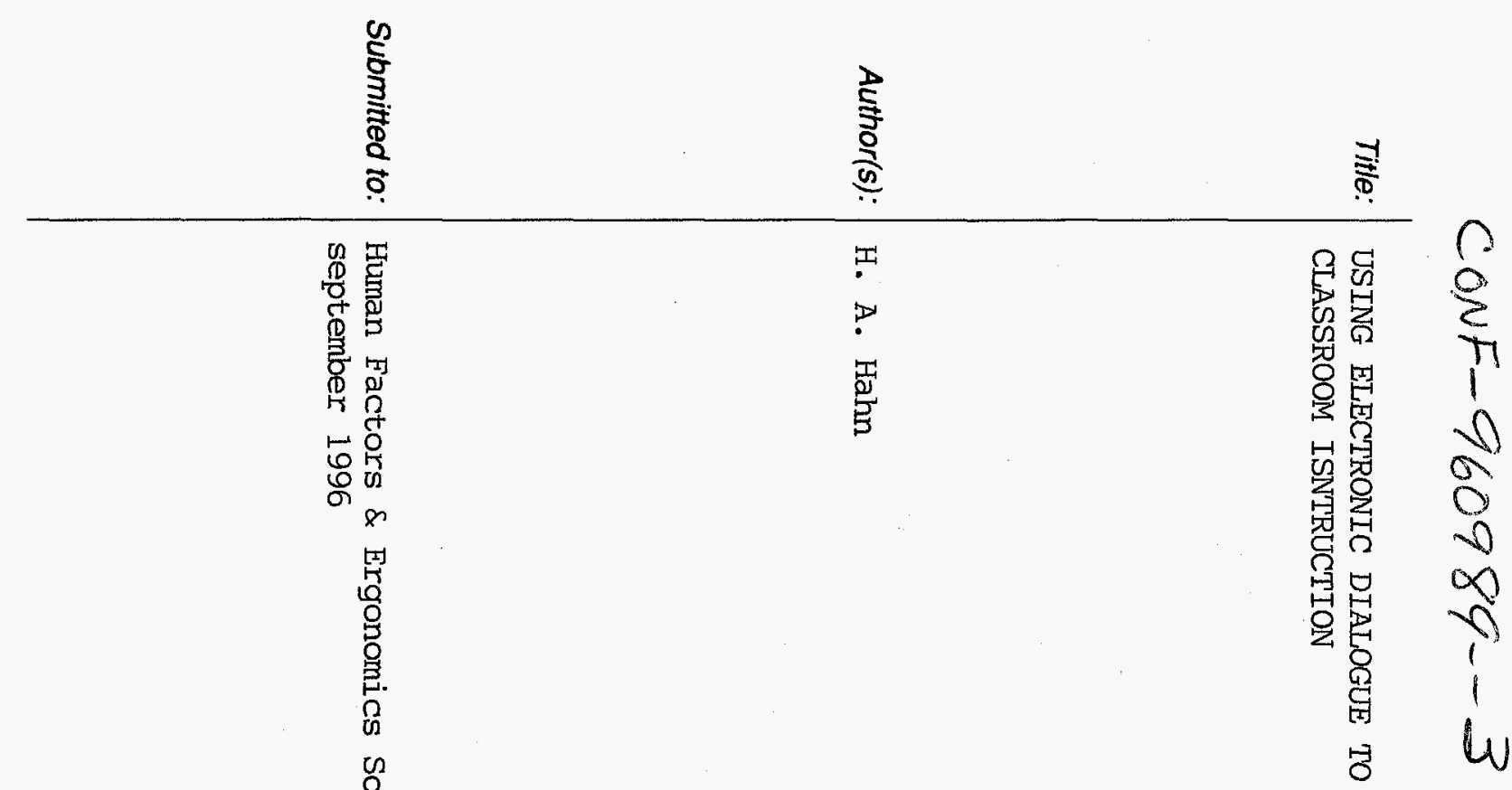
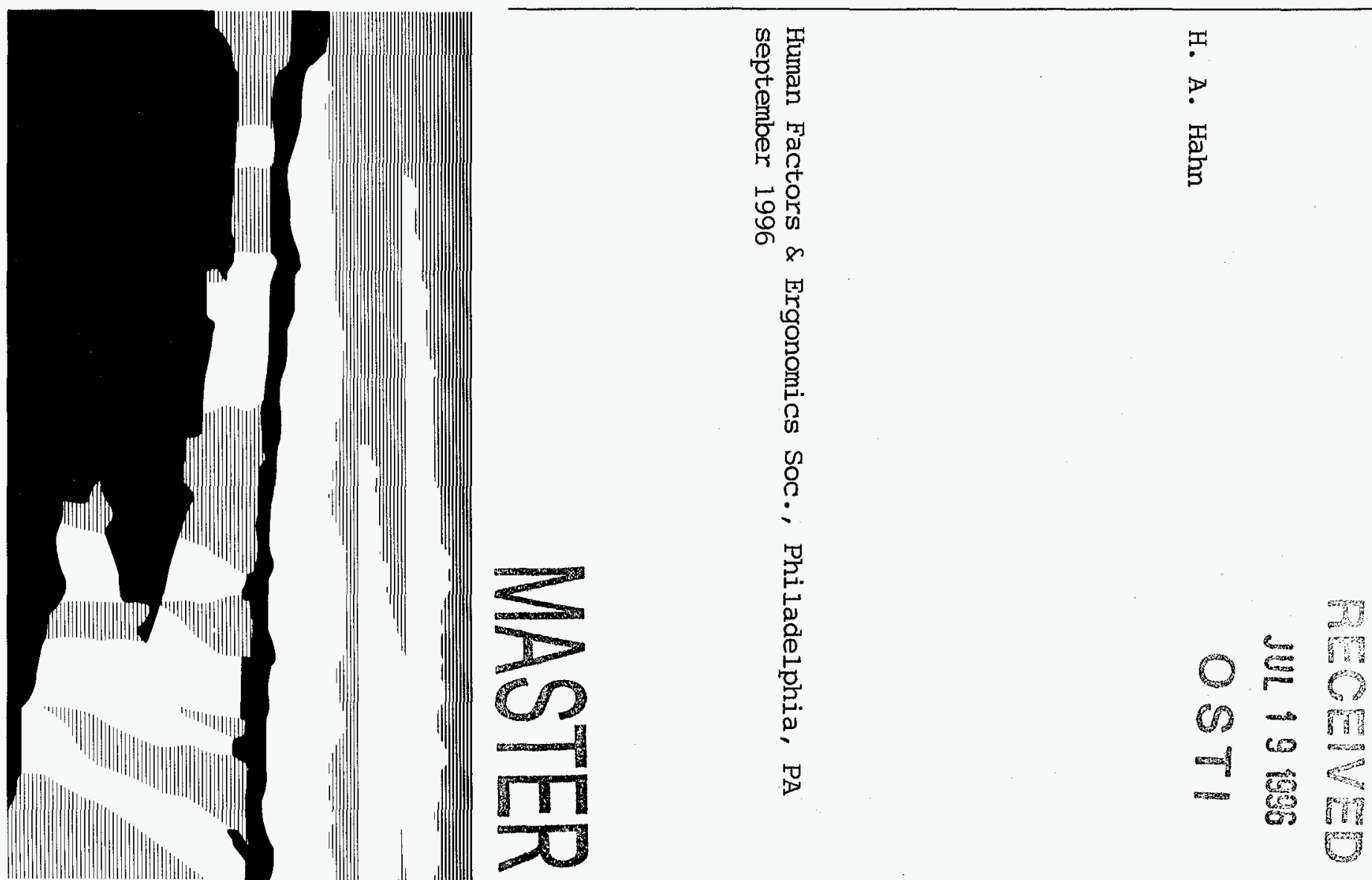


\section{DISCLAIMER}

Portions of this document may be illegible in electronic image products. Images are produced from the best available original document. 


\title{
USING ELECTRONIC DIALOGUE TO AUGMENT TRADITIONAL CLASSROOM INSTRUCTION
}

\author{
Heidi Ann Hahn \\ Los Alamos National Laboratory \\ Los Alamos, New Mexico 87545
}

\begin{abstract}
This paper demonstrates how an electronic dialogue with a panel of human factors experts was used effectively as an augmentation to traditional classroom instruction. Nine students spent a one and one-half hour class session using a variety of commercial electronic mail software packages available on their own desk-tops (not in a university computer lab) to engage in discussion with remotely distributed instructors on topics generated by the students themselves. Ninety eight messages were exchanged, with about $60 \%$ having technical content. Interaction content and style were analyzed, and a survey was distributed to participants to evaluate the session. Process observations by this author augmented these data. Strengths and weaknesses of using technology not specifically designed for this function are discussed.
\end{abstract}

\section{INTRODUCTION}

During the Fall semester of academic year 1995, I had the opportunity to teach an introductory graduate level human factors course in the Mechanical Engineering Department at a branch campus of the University of New Mexico. This course was funded as part of an Advanced Research Projects Agency (ARPA) Technology Reinvestment Project (TRP) called "Semiconductor/Electronics Manufacturing Experts in the Classroom." The fundamental premise of the project was that both education at the university level and continuing education of professionals in industry could be enhanced by incorporating practical messages of experts in the subject matter area into more traditional instructional methods. Key activities of the overall project included:

- Developing new courses related to manufacturing engineering, utilizing outside technical experts for a variety of activities such as lectures, tours, practicums, mentoring, or panel discussions; and - Disseminating such courses via instructional television (ITV) networks not only to the university campus but also to sites at companies, federal laboratories, technology centers, and other universities.

In agreeing to teach the course (which was a new one for the department), I accepted responsibility to bring several (preferably at least five) Ph.D.-level "experts" into the classroom to provide instruction in whatever fashion suited the course objectives. Because the density of human factors practitioners in this geographic area is quite small, my aspirations of bringing local experts into the classroom for live lectures or using instructional television to "pipe" lectures up from the main campus fell short of my commitment.

The desirability of using ITV for projectsupported courses led to thoughts about the adequacy of other electronic media, in this case simple electronic mail, as a mechanism for involving students with outside experts. Most of us have probably had experience with using email as a means of communicating with a course instructor or our students, but this tends to be a simple question-andanswer exchange, and is generally invisible to other class participants. On the other extreme, I have also been involved in a project in which the entire course was taught in an electronic classroom, with no live instruction. Although this project was successful, it provided a poor model for the electronic dialogue that I was proposing for the human factors course, as it had the advantages of (1) having a built-in conferencing structure that allowed visibility of dialogue to all participants and (2) allowing dialogue, and its attendant social behaviors, to emerge over time, such that the richness of the dialogue built through the duration of the multi-month course. (For more information, see Hahn, Ashworth, Phelps, and Byers, 1990.)

This paper demonstrates how an electronic dialogue with a panel of human factors experts was used effectively as an augmentation to traditional classroom instruction. Further, the strengths and weaknesses of using technology not specifically designed for this function are addressed. 
ABOUT THE DIALOGUE SESSION

On December 5, 1995, three human factors professionals served as members of a panel discussing student-generated topics of interest with nine students in an introductory human factors course. The primary course instructor, also a human factors practitioner (rather than a university professor), served a coordinating function for the dialogue.

All students were adult learners, and all were employed by a federal laboratory operated for the Department of Energy (DOE). Thus, potential guest panelists were invited from within the DOE complex (a total of seven invitations was extended), and a theme for the discussion of "Human Factors in the DOE Complex" was selected. Guest panelists were geographically dispersed, with locations ranging from Washington state to Tennessee.

The dialogue took place during the normally scheduled class time (a one and one-half hour block in the early evening), with students remaining at their home or office computer stations rather than coming to the usual classroom. No special software was distributed, so a variety of commercially available electronic mail software packages were being used simultaneously. Advance information about the backgrounds of the guests was disseminated, but no other pre-work (either computer set-up or framing questions) occurred prior to class time.

At the beginning of the session, a welcome message containing computer set-up instructions was disseminated to all participants, who were asked to check in to make their presence known. When the majority of the class was ready, the coordinator sent out a seed question designed to get the dialogue started. From that point on, all questions were student-generated, until the closing message was sent by the coordinator. This closing message contained instructions for restoring computers for normal use and a survey assessing satisfaction with the dialogue. Both students and instructors were asked to respond to the survey.

\section{SOURCES OF INFORMATION}

Data sources include analysis of the content and volume of all message traffic; survey results, including both ratings and comments from the participants; and process observations by the primary instructor.

\section{FINDINGS}

\section{Message Traffic Analysis}

In all, a total of 98 messages was exchanged. Of these, 16 were generated by the coordinator, 44 by the guest instructors, and 38 by the students. The coordinator intentionally refrained from joining technical content dialogues. As discussed below, this may have been a mistake in terms of the depth of dialogue achieved.

Roughly $40 \%$ (41 in number) of the messages had logistics regarding set-up or session closure and/or social exchange as their content, with the remainder addressing technical issues. The messages having technical content can be categorized into three broad subject areas, including education and career development, experiences of the practitioners, and specific technical questions on a variety of subjects prompted by biographical information that revealed areas of expertise of the lecturers. Table 1 shows the distribution of comments in each subject area and further subcategorizes each area into more specific discussion topics.

Interaction styles were also examined in the technical content areas. For each of the 15 subtopics, a determination was made regarding the level of dialogue that had occurred. Here, the analysis unit was an "exchange," which is defined as all of the transactions or individual messages that occurred between when a question was posed and when the dialogue was brought to closure.

Exchanges occurred in three categories: (1) seven exchanges $(47 \%)$ were characterized as dialogue, in which more than one volley of messaging occurred, either through follow-up questioning by a student or addition of comments by an instructor other than the first respondent; (2) six exchanges $(40 \%)$ were deemed to be question and answer, in which only a single volley of message exchange occurred; this was characterized by a student posing a question and receiving an answer from a single instructor; and (3) two comments (13\%) were called "no exchange"; in these cases a question was posed but never received a response. Of these two, one was closely aligned with another sub-topic, and the instructors may have thought it had been adequately answered in that context.

\section{Survey Results}

Student responses. Six of the nine students (67\%) responded to an eight-item survey which assessed the educational value, pace, and logistics for the session. Survey participation was entirely 
Table 1. Frequency of comments by topical area.

\begin{tabular}{|l|l|}
\hline Topic & Number of Comments \\
\hline Education and Career Development & \multicolumn{2}{|l|}{} \\
-- Engineering vs Psychology Background & 8 \\
-- Blending the Disciplines & 1 \\
-- Available University Programs & 9 \\
\hline Experiences of Practitioners & \\
-- Overcoming Resistance to HF & 15 \\
-- Identifying HF "Hot Topics" & 6 \\
-- Good vs Bad Aspects of Job & 6 \\
& 3 \\
\hline Specific Technical Questions & 24 \\
-- Virtual Reality & 7 \\
-- Data Collection Methods & 4 \\
-- Scientific Visualization & 2 \\
-- Safety Analysis & 2 \\
-- Prototyping & 2 \\
-- Defining Performance vs Productivity & 1 \\
-- Usability Testing & 2 \\
-- Sample Size & 2 \\
-- Data Applications & 2 \\
\hline
\end{tabular}

voluntary, and students were instructed that neither their decision to fill out the survey nor their answers would have any effect on their course grade. (Because the survey was administered via email, anonymity could not be offered.)

As shown in Table 2, median responses were in the neutral to satisfied range for all items. Negative responses (both ratings and written comments) occurred primarily with respect to the number of instructors (students thought the sessions would have benefited by having more than three lecturers) and logistics. Two major concerns arose regarding logistics: (1) that computer set-up should have been done and verified in advance and (2) $80 \%$ of the students wrote in comments indicating that they wanted the opportunity to formulate questions in advance.

Instructor responses. Two of the three instructors responded to the same survey that was administered to the students. As was the case with the student ratings, median responses were in the neutral to satisfied range for all items. Contrary to student requests to do pre-work, both instructors noted that the session had been "painless" in part because of the very limited advance preparation requirements.

Comments. Comparison of the responses of students and instructors shows that the instructors viewed the educational objective aspects of the session more positively than did the students, although the students had a more positive view of the breadth of topics covered -- perhaps because they were generating questions on topics of interest to them.

Students had a slightly more favorable view of the dimensions related to message traffic. Session length and logistics were viewed equally favorably (with a median rating of 4 , which means "satisfied") by both groups. The latter result is interesting, as one-third of the members of each group experienced technical difficulties.

Finally, both groups were least satisfied with the number of instructors. All who had a negative view on this dimension thought that having more instructors would have improved the breadth and liveliness of the discussion. 
Table 2. Survey responses.

\begin{tabular}{|c|c|c|}
\hline$\frac{\text { Question }}{\text { (1 to } 5 \text { rating scale, unless otherwise noted) }}$ & $\frac{\text { Median Student }}{\underline{\text { Response }}}$ & $\frac{\text { Median Instructor }}{\underline{\text { Response }}}$ \\
\hline Educational value of the session objective & 4 & 4.5 \\
\hline Degree to which the session met the session objective & 3 & 4.5 \\
\hline Number of guest lecturers participating & 3 & 3.5 \\
\hline Traffic volume (\# of messages) & 4 & 3.5 \\
\hline Traffic pace (how fast it flowed) & 4 & 3.5 \\
\hline Breadth of topics covered & 4 & 3.5 \\
\hline Length of the session & 4 & 4 \\
\hline Logistics (around the use of the technology) & 4 & 4 \\
\hline $\begin{array}{l}\text { Would you participate in this kind of a "class" again? } \\
(\mathrm{Y} / \mathrm{N})\end{array}$ & $100 \%$ Yes & $100 \%$ Yes \\
\hline
\end{tabular}

\section{Process Observations}

The first observation actually occurred prior to the start of the session, and involves the difficulty in obtaining agreements to participate (without compensation) by panelists. Two rounds of contacting potential panelists yielded only $43 \%$ of the possible population. No systematic attempt was made to follow-up on the reasons for nonparticipation. Most who chose not to participate did not respond to the request at all; one person expressed an interest in what we were doing but had a time conflict that prevented his participation.

Second, a decision was made prior to the session to not do advance computer set-up so as to minimize extracurricular demands for students and faculty. This approach backfired, as at least two of the students and one instructor were unable to broadcast to all participants for some portion of the session.
On a balancing note, however, for those people for whom the computer set-up worked as planned, observation of the exchanges showed that many of the characteristics of electronic bulletin boards were emulated using normal email channels. Given that participants were asked to set their computers to check for new mail every two minutes, responses were rapid -- most checks had at least one new message, and delays in responding were rarely longer than four minutes. Further, an instruction to append new comments to the last relevant message helped ensure that a coherent running dialogue was disseminated with each new transaction.

Fourth, when the session ended, several of the exchanges still appeared to be active. Therefore, the email address was left open for an additional several days so that the dialogues could continue, and participants were made aware of its availability. 
Interestingly, other than to return surveys, the address was not used.

Finally, as noted above, only about half of the exchanges were real dialogues, and even those were short (usually consisting of only two volleys). Exchanges would have been richer and more satisfying had more and lengthier dialogues occurred.

\section{DISCUSSION}

Our experience with this session demonstrated that an electronic dialogue with a panel of human factors experts could be conducted effectively, without the use of specialized equipment, as an augmentation to traditional classroom instruction. Several weaknesses with the approach were identified, including needs to use more instructors and to invest more advance preparation time in setting up and checking out the computer links. One drawback to this advance set-up, however, is that some of the suggested settings (for example, an email-checking frequency of every two minutes) are inappropriate for normal business use. Thus, the computer set-up would have to occur as a dry run that would be reversed rather than allowing the settings to remain until class time.

Differences in time zone created problems for one of the instructors. Here, the balance is between the excitement generated by synchronicity and convenience to the participants. In circumstances similar to what we had in this class, where all of the students and two of the four instructors were in one time zone, I would argue for synchronous exchanges. With greater degrees of geographical dispersion among participants or in cases where participants live in more than just the four time zones of the continental U. S., mandated synchronicity might be inconvenient to the point of preventing some potential participants from engaging in the dialogue at all. There, allowing for asynchronous communication (in which participants could leave email messages at any time they wished during some constrained period, say, of several days) might be appropriate.

In spite of students' opinions that they should have the opportunity to formulate questions and send them to the instructors in advance, I would resist this advice, as it runs a real risk of removing the spontaneity and non-linearity that made the session stimulating. Interestingly, students did have biographical information about one of the instructors several days before the session and received information about the other two teachers a few hours prior to the session, but there was no evidence that they had used that information to frame questions prior to the beginning of the class period.
At the same time, interventions are needed to emphasize dialogue over simple question-and-answer exchanges. Better instructions to both students and faculty indicating that adding on to someone else's question or answer is appropriate and encouraged would likely help this situation. Also, the coordinator should take a more active role in keeping conversations going, either through joining the conversation him- or herself or by having side conversations (not visible to students) prompting additional comments by instructors.

\section{ACKNOWLEDGMENTS}

Thanks are due to Dr. John Wood at the University of New Mexico for supporting this course as part of his TRP grant. The assistance of Drs. John Draper (Oak Ridge National Laboratory), Daniel Donohoo (Pacific Northwest Laboratory), and Susan Hill (Idaho National Laboratory) in conducting the expert dialogue panel was greatly appreciated.

This work was supported in part by the Department of Energy under contract W-7405-ENG36.

\section{REFERENCES}

Hahn, H. A., Ashworth, R. L. Jr., Phelps, R. H., and Byers, J. C. (1990). Performance, throughput, and cost of in-home training for the Army Reserve: Using asynchronous computer conferencing as an alternative to resident training. Proceedings of the Human Factors Society 34th Annual Meeting, Orlando, FL, 1417-1421. 